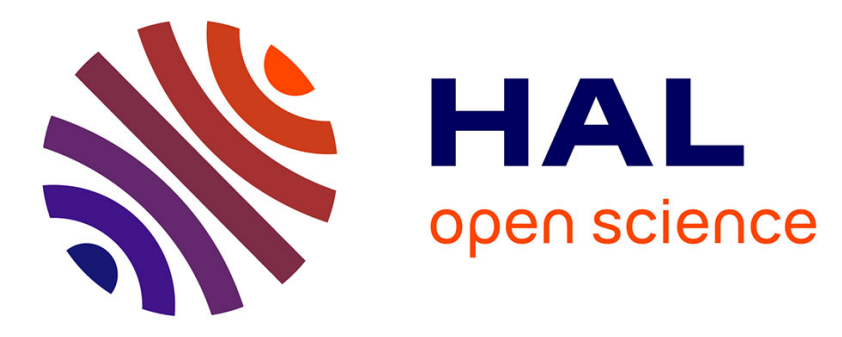

\title{
Open cracks depth sizing by multi-frequency laser stimulated lock-in thermography combined with image processing
}

Steve Beuve, Zihi Qin, Jean-Paul Roger, Stéphane Holé, Christine Boué

\section{- To cite this version:}

Steve Beuve, Zihi Qin, Jean-Paul Roger, Stéphane Holé, Christine Boué. Open cracks depth sizing by multi-frequency laser stimulated lock-in thermography combined with image processing. Sensors and Actuators A: Physical , 2016, 10.1016/j.sna.2016.06.028 . hal-01346003

\section{HAL Id: hal-01346003 \\ https: / hal.sorbonne-universite.fr/hal-01346003}

Submitted on 18 Jul 2016

HAL is a multi-disciplinary open access archive for the deposit and dissemination of scientific research documents, whether they are published or not. The documents may come from teaching and research institutions in France or abroad, or from public or private research centers.
L'archive ouverte pluridisciplinaire HAL, est destinée au dépôt et à la diffusion de documents scientifiques de niveau recherche, publiés ou non, émanant des établissements d'enseignement et de recherche français ou étrangers, des laboratoires publics ou privés. 
Open cracks depth sizing by multi-frequency laser stimulated lock-in thermography combined with image processing

Steve Beuve ${ }^{1}$, Zihi Qin ${ }^{1}$, Jean-Paul Roger ${ }^{2,3}$, Stéphane Holé ${ }^{1,4,5}$, Christine Boué $e^{1,4,5}$

${ }^{1}$ Sorbonne Universités, UPMC Univ Paris 06, F-75005 Paris, France

${ }^{2}$ CNRS, UMR 7587, F-75005, Paris, France

${ }^{3}$ Institut Langevin, PSL Research University, ESPCI ParisTech, 1 rue Jussieu, F-75005, Paris, France

${ }^{4}$ LPEM, PSL Research University, ESPCI-ParisTech, 10 rue Vauquelin, F-75005 Paris, France

${ }^{5}$ CNRS, UMR 8213, F-75005 Paris, France 


\section{Highlights}

the multi-frequency lock-in infrared thermography method is used to evaluate perpendicular crack depths.

the experimental curves of the spatial second derivative (Laplacian) of the amplitude and of the phase of the infrared signal are analyzed as a function of the thermal diffusion length.

direct depth indicators depending on both the Laplacian of amplitude and phase images are introduced. experimental measurements validate the method for crack depths ranging from about 0.5 to $3 \mathrm{~mm}$ in metallic material.

\section{Abstract}

The multi-frequency lock-in thermography is coupled with efficient image processing to analyse infrared open crack footprint. It has been shown that the evolution of the Laplacian of modulated surface temperature amplitude image as a function of the diffusion length allows to estimate the depth of surface open defects but requires calibration abacus obtained by finite element method simulations. In this work, a method is proposed to avoid the tedious use of abacus by introducing an indicator of the crack depth using a simple expression depending on the Laplacian of both amplitude and phase images. This multi-frequency method is presented through numerical simulations. Besides, the analysis of experimental results obtained on artificial and real open vertical cracks in metallic samples show that the depth of the defects can be directly estimated.

Keywords: lock-in; thermography; crack depth; modulation frequency; infrared images; non destructive control.

\section{Introduction}

Structures submitted to cyclic mechanical loading can develop cracks which can be highly damaging. The depth of a crack is an important information to access its dangerousness. But this information is not easy to obtain. Liquid penetrant, the most conventional method to detect open cracks [1], cannot give worth quantitative information on crack depths. Quantitative estimation can be provided by using 
methods like ultrasonically stimulated thermography, eddy current stimulated thermography or laser thermographic imaging [2-5]. But these techniques, which are based on the analysis of the generated local rise of the crack temperature, need calibration procedures, a reference response and/or blackened sample to evaluate the crack depth [6-16].

Lock-in thermography uses lateral thermal flows in order to detect vertical cracks [12-15]. The amplitude and phase of infrared images obtained by the diffusion of lateral thermal flows provide information concerning defects with a good contrast for vertical cracks. Reference [17] proposes an analytical solution of the temperature distribution to deduce the crack width for infinite vertical cracks.

In this work a lock-in thermography procedure is used for depth evaluation of surface-breaking cracks in metals without surface preparation and with no calibration procedure. The implementation of the approach is described in [18-21]: taking advantage of the thermal diffusion length to probe different regions of the sample, the analyse of the amplitude images at the modulation frequency allows to provide crack depth determination but this requires abacus or back simulations to obtain quantitative information. The improvement provided by this work is to process the phase images in addition to the amplitude images to directly allow the determination of depth indicators, avoiding thus the calibration abacus used up to now.

In the first part of this article, the study is led from results of 3D FEM numerical simulations to introduce two depth indicators $\left(\mu_{\mathrm{A}}\right.$ and $\left.\mu_{\varphi}\right)$ which rely on the evolution of the second spatial derivative of both amplitude and phase images as a function of the thermal diffusion length.

In the second part of this article, experimental results obtained on constant controlled "cracks" in steel and aluminum blocks are analyzed and a global depth indicator $I_{h}$ calculated from $\mu_{\mathrm{A}}$ and $\mu_{\varphi}$ is proposed. Finally, this global indicator $I_{h}$ is applied to Inconel samples exhibiting real fatigue cracks. 


\section{Multi-frequency lock-in infrared thermography method}

2.1. Principle of the method

The presented method uses a modulated heat excitation associated with lock-in thermography. When a modulated circular laser spot excitation heats the sample surface, the 3D heat transfer equation in solids in the absence of internal heat generation can be used to evaluate the temperature distribution in the whole solid [22]. The lock-in processing of the signals allows a retrieval of both amplitude and phase of the sinusoidal infrared radiation component from the surface sample at the heating fundamental frequency. The unwanted continuous heating (DC) component is thus filtered out. The second spatial derivatives (Laplacian) of both amplitude and phase images highlight the thermal disturbance caused by the presence of a vertical crack. Crack pixels are extracted from the Laplacian of the amplitude image according to the numerical procedure presented in [23].

In a modulated heating process, the thermal diffusion length, which can be written as

$$
\mu=\sqrt{\frac{\alpha}{\pi f}}
$$

where $\alpha$ is the thermal diffusivity of the specimen, can be adjusted by the modulation frequency $f$ of the thermal excitation source and used as a 3D probe of the crack depth $h$. The crack signature is analyzed via the changes of the Laplacian of the amplitude and phase images as a function of the thermal diffusion length $\mu$.

The absolute value of the Laplacian of the amplitude image normalized by its asymptotic value is denoted $\Lambda_{N}$ and the value of the Laplacien of the phase image is denoted $\Lambda_{\varphi}$. In [18,19], it is shown that $\Lambda_{N}(\mu)$ at the crack pixels reach their maximal value at a thermal diffusion length increasing with $h$ and that the evolution of $\Lambda_{N}(\mu)$ is independent of the crack width. So the evolution of $\Lambda_{N}$ with $\mu$ is then an indicator of the crack depth. In [19], simulated $\Lambda_{N}(\mu)$ for various excitation frequencies are used as an abacus to deduce the depth of real cracks. However, these simulations are time consuming (several hours) and must be done for every kind of sample. Besides obtaining the results 
more quickly, the results do not depend on modeling accuracies. It is thus a great interest to have a direct indicator, independent of the material and its surface condition, to estimate the crack depth.

\subsection{Simulated experiments}

The objective of this work is to combine the analysis of $\Lambda_{N}(\mu)$ and $\Lambda_{\varphi}(\mu)$ of crack responses to easily deduce quantitative indicators of the crack depth without any simulation abacus.

The heat source is focused onto the surface in a circular and uniform spot of radius $r$ at a distance $d_{0}$ of a linear crack perpendicular to the surface of width $w$, length $L$ and constant depth $h$. The heat source is intensity modulated at a frequency $f$. Amplitude and phase images of the modulated surface temperature at the frequency $f$ are calculated for different $h$ values by 3D FEM numerical simulations. Figure 1 shows an example of amplitude (Figure 1a) and phase (Figure 1b) images of $400 * 400$ pixels (1 pixel sees $50 \mu \mathrm{m} * 50 \mu \mathrm{m}$ ) obtained at $f=0.8 \mathrm{~Hz}$. The linear crack footprint is clearly visible in the figures above the heat source. A set of pixels $\mathrm{P}(\mathrm{x}, \mathrm{y})$ located on the crack which faces the heating zone are extracted from the Laplacian of the amplitude image with a basic numerical processing described in [23] (Figure 2a). Figure 2b shows the Laplacian of the phase for these $\mathrm{P}(\mathrm{x}, \mathrm{y})$ pixels at $f=0.8 \mathrm{~Hz}$. The distance between a pixel $\mathrm{P}(\mathrm{x}, \mathrm{y})$ and the center of the heating spot is denoted as $d(x, y)$.

\subsubsection{One point analysis}

The evolution of the Laplacian of the amplitude $\Lambda_{N}$ as a function of the thermal diffusion length at the closest pixel P to the heating spot $\left(d(x, y)=d_{0}\right)$ is reported in Figure 3. Simulation results are presented for four depths $h$ as a function of $\mu_{\mathrm{i}}=\sqrt{\alpha / \pi f_{i}}$ for a frequency ranging from $0.05 \mathrm{~Hz}$ to $1.5 \mathrm{~Hz}$.

The polynomial fits $f_{h}(\mu)$ of $\Lambda_{N}\left(\mu_{i}\right)$ show a shift along the $\mu$ axis which depends on the simulated depth $h$. Afterward in this work, the value of $\mu_{A}$ corresponding to $f_{h}\left(\mu_{A}\right)=0.7$ is then considered as a first indicator for the crack depth evaluation.

The evolution of the absolute value of the Laplacian of the phase images at the same pixel P can also be analyzed. One notices in Figure 4 that the polynomial fits of simulated $\Lambda_{\varphi}(\mu)$ reach a maximum for 
$\mu=\mu_{\varphi}$ which is of the order of the crack depth. $\mu_{\varphi}$ is thus retained as a second indicator for the crack depth evaluation.

Figure 5 shows that the indicator $\mu_{\varphi}$ deduced from the simulations seems to be more dependant on the crack depth $h$ than the indicator $\mu_{A}$.

\subsubsection{Synthesis of crack point analysis}

Let's consider the responses of 50 selected pixels on the crack at $f=1.5 \mathrm{~Hz}$. Figure 6 displays $\mu_{\mathrm{A}}$ and $\mu_{\varphi}$ as a function of the distance $d$ between a selected pixel and the center of the heating spot for the four simulated depths $h$.

One notices in Figure 6 that $\mu_{A}$ is more $d$ dependant than $\mu_{\varphi}$. Therefore a combination of $\mu_{A}$ and $\mu_{\varphi}$ is proposed to minimize the influence of $d$ and thus directly estimate the local depth for each selected pixels.

\section{Experimental results for the evaluation of the depth}

\subsection{Experimental set-up and methodology}

The experimental set up (Figure 7) includes a heat source (a diode-pumped Ytterbium laser with $830 \mathrm{~nm}$ wavelength and tuneable power), a signal generator which modulates the intensity of the heat source at frequency $f$, and an infrared camera (Jade III, CEDIP, FLIR). The camera has an array ( $240 * 320$ pixels) of InSb detectors sensitive in the 3-5 $\mu \mathrm{m}$ wavelength range.

The laser beam is focused onto the surface in the vicinity of the crack in an approximately uniform and circular spot of $1 \mathrm{~mm}$ diameter. No surface preparation is required for the studied samples. The laser power is adjusted to the thermal response of the samples.

The generated infrared signals measured by the camera and the reference frequency $f$ are sent to a lock-in detection module (FLIR R9902). The amplitude and phase images of the $f$-component of the IR 
emission induced at the surface of the inspected sample is then extracted with a fairly good contrast (Figure 8a and Figure 8b).

The Laplacian of amplitude and phase images (Figure 8c and 8d) are proceeded according to the procedure described in the former section to calculate $\mu_{A}$ and $\mu_{\varphi}$ from the polynomial fits of $\Lambda_{N}(\mu)$ and $\Lambda_{\varphi}(\mu)$ (Figure 9). Notice that local diffusivity $\alpha$ of each sample can be directly extracted from measurements [24], in a homogeneous area sufficiently far away from the crack.

\subsection{Experimental measurements with controlled artificial cracks}

Artificial cracks with controlled dimensions are good samples to validate experimentally the simulated results presented in section 2 .

Two $40 * 40 * 20 \mathrm{~mm}^{3}$ steel and aluminum alloy plates separated by a brass sheet of $30 \mu \mathrm{m}$ thickness are assembled with screws to simulate a sample with a vertical open crack (Figure 10). In the presented results, the brass sheet was cut in $z$ direction so as to leave an air gap of controlled constant depth between two steel plates (Samples F, thermal diffusivity equal to $3.7 \pm 0.210^{-6} \mathrm{~m}^{2} / \mathrm{s}$ ) or two aluminum alloy blocks (sample G, thermal diffusivity equal to $40 \pm 210^{-6} \mathrm{~m}^{2} / \mathrm{s}$ ) as described in Table 1 . The laser power is $4 \mathrm{~W}$.

Figure 11 shows $\mu_{A}$ and $\mu_{\varphi}$ as a function of the distance $d$ obtained for the four studied samples. One can observe that $\mu_{A}$ and $\mu_{\varphi}$ follow the same trends as simulation results (Figure 6) : $\mu_{A}$ and $\mu_{\varphi}$ are both dependant on $h$ and $\mu_{\varphi}$ is less $d$ dependant than $\mu_{A}$ but $\mu_{\varphi}$ is noisier than $\mu_{A}$ in the presented experimental results.

\subsection{Global depth indicator}

In order to minimize the dependence on $d$ of $\mu_{A}$ and $\mu_{\varphi}$ and to give an enhanced robustness to the depth assessment at each selected pixel, a new depth indicator $I_{h}$ depending on $\mu_{A}, \mu_{\varphi}$ and $d$ is defined as:

$$
I_{h}(x, y)=\frac{\mu_{A}(x, y) * \mu_{\varphi}(x, y)}{a * d(x, y)}
$$


where $a$ is an adjustment parameter. For depth range from $0.5 \mathrm{~mm}$ to $3 \mathrm{~mm}$ and for the experimental conditions, $a=2$ is well adapted as shown hereafter.

Figure 12 shows the depth indicator $I_{h}$ obtained with the presented multi-frequency lock-in thermography method using (2) with $a=2$ for the four samples. The results are presented in x,y plane with the same color scale to give a comparative and visual indication of the depth for each selected pixels of the 4 cracks. The experimental results seem coherent with the expected $h$ values.

Figure 13 displays the average value over the selected pixels $\mathrm{P}(\mathrm{x}, \mathrm{y})$ of $\mu_{A}(x, y), \mu_{\varphi}(x, y)$ and $I_{h}(x, y)$, respectively denoted as $\tilde{\mu}_{A}, \tilde{\mu}_{\varphi}$ and $\tilde{I}_{h}$ obtained for the four samples as a function of expected depths. Linear regressions through the origin are calculated for the three indicators. The R-squared coefficient $\mathrm{R}^{2}$ which represents the correlation between the predictive value and the average of the indicators show that $\tilde{I}_{h}$ indicator is the better indicator $\left(\mathrm{R}^{2}\right.$ near 1$)$. The negative $\mathrm{R}^{2}$ coefficient obtained for $\tilde{\mu}_{A}$ is nonsense and indicates that the linear fitting through the origin is not appropriate. As $\mu_{A}$ and $\mu_{\varphi}$ are correlated measurements, the error bars of the $\tilde{I}_{h}$ indicators are smaller than the error bars of $\tilde{\mu}_{A}$ and $\tilde{\mu}_{\varphi}$ indicators. One can see that the indicator $\tilde{I}_{h}$ is comparable to the expected depth $h$, though a bias exists for small depths.

The results validate the method to evaluate constant crack depths within the tested depth range from 0.7 to $2.5 \mathrm{~mm}$.

\subsection{Inconel samples with real fatigue cracks}

Five open vertical fatigue cracks of 35 to $65 \mu \mathrm{m}$ widths in a highly reflecting $130 * 27 * 9 \mathrm{~mm}^{3}$ Inconel plates (samples A, B, C, D, E) are opened over the entire width of the samples. Depths are measured on the 2 lateral sides of the sample using optical microscopy [18] (Table 2). The measured thermal diffusivity of the Inconel sample is equal to $3.3 \pm 0.110^{-6} \mathrm{~m}^{2} / \mathrm{s}$. The laser power is $2 \mathrm{~W}$.

Figure 14 shows $I_{h}$ using (2) with $a=2$ in (x,y) planes for Inconel samples. 
Figure 15 presents the averaged indicators $\tilde{\mu}_{A}, \tilde{\mu}_{\varphi}$ and $\tilde{I}_{h}$ calculated from selected pixels of the crack as a function of expected averaged depth $h$. Linear regressions through the origin are calculated for the three indicators. The R-squared coefficient $\mathrm{R}^{2}$ is nearer to 1 for $\tilde{\mu}_{\varphi}$ than for $\tilde{I}_{h}$ and has no sense for $\tilde{\mu}_{A}$. If the result obtained for sample $\mathrm{E}(h>3 \mathrm{~mm})$ is ignored, the linear regression for $\tilde{I}_{h}$ gives comparable results to those obtained for steel and aluminum samples (figure 13): $R^{2}=0.92$ and $\mathrm{y}=0.92 \mathrm{x}$.

Consequently, $\tilde{I}_{h}$ seems to be a good direct indicator of the depth $h$ at least for $h$ lesser than $3 \mathrm{~mm}$. Although it seems that the sensitivity of the measurement reaches its limit for Sample E, the proposed multi-frequency lock-in thermography approach appear to be promising to locally probe local crack depth without sample modelling .

\section{Conclusion}

In this work, the multi-frequency lock-in infrared thermography method is used to evaluate perpendicular crack depths. A specific empirical data analysis is presented using the experimental curves of the spatial second derivative (Laplacian) of both amplitude and phase infrared images as a function of the thermal diffusion length. Two direct depth indicators $\mu_{A}$ and $\mu_{\varphi}$ are introduced and their evolution as a function of the crack depth $h$ and the distance $d$ of the crack to the heating spot are analyzed. A combination of $\mu_{A}, \mu_{\varphi}$ and $d$ is used to make a depth indictor $I_{h}$ independent of distance $d$. It can be seen as a compromise which enhances the robustness of the depth evaluation.

Measurements were carried out on Inconel alloy samples with calibrated $0.5 \mathrm{~mm}$ to $3.5 \mathrm{~mm}$ crack depths. The measurement duration depends on the number of used frequencies. Typically for metals, one can consider 5 different frequencies between $0.05 \mathrm{~Hz}$ and $1.5 \mathrm{~Hz}$ which lead to 10 minutes measurement duration. The distance of heat source to the inspected crack and the frequencies selected to probe the volume of the sample must be thoroughly chosen so that the sensibility is optimal. This distance depends on the thermal diffusivity of the sample. The depth range for the studied material is from about 0.5 to $3 \mathrm{~mm}$.

\section{Acknowledgments}

The authors would like to thank Areva Intercontrole for providing Inconel samples with various calibrated fatigue cracks 


\section{References}

[1] L. Cartz. Nondestructive Testing, ASM International, Materials Park, Ohio 1995.

[2] D.P. Almond, B. Weekes, T. Li, S.G. Pickering, E. Kostson, J. Wilson, G. Y. Tian, S. Dixon, S. Burrows, Thermographic techniques for the detection of cracks in metallic components. Insight - Non-Destructive Testing and Condition Monitoring, Vol 53, Number 11, November 2011, pp. 614-620 (7)

[3] J.-C . Krapez, L. Legrandjacques, F. Lepoutre, D. Balageas, optimization of the photothermal camera of crack detection, QIRT 1998 Archives: Documents and sessions presented during the 4th conference on QIRT (Lodz, Poland), 1998

[4] B. A. Auld and J. C. Moulder, Review of Advances in Quantitative Eddy Current Nondestructive Evaluation, Journal of Nondestructive Evaluation, Vol. 18, No. 1, 1999

[5] A. Dillenz, T. Zweschper, G. Riegert, G. Busse, "Progress in phase angle thermography". Rev. of Sci. Instrum vol. 74, pp. 417-419, 2003.

[6] M. Morbidini, P. Cawley, A calibration procedure for sonic infrared nondestructive evaluation. Journal of Applied Physics 106, 023504, 2009

doi: $10.1063 / 1.3169518$

[7] B. Weekes, D. P.Almond, P. Cawley, Tim Barden, Eddy-current induced thermographyprobability of detection study of small fatigue cracks insteel,titanium and nickel-based super alloy, NDT\&E Int. 49 47-56, 2012

[8] J. Schlichting, Ch. Maierhofer and M. Kreutzbruck, Crack sizing by laser excited thermography, NDT\&E Int. 45, 133-140, 2012

[9] T. Li, D. P. Almond, Rees S., crack imaging by scanning pulsed laser spot thermography, NDTE Int 44(2), 216-25, 2011

[10] O. Wysocka-Fotek, W. Oliferuk, M. Maj, Reconstruction of size and depth of simulated defects in austenitic steel plate using pulsed infrared thermography, Infrared Physics \& Technology 55 363-367, 2012

[11] S. Lugin, Detection of hidden defects by lateral thermal flows. NDT\&E Int. Vol 56 pp: 48-55, 2013

[12] T. Sakagami, S. Kubo, Y. Teshima, 'Fatigue crack identification using near-tip singular temperature field measured by lock-in thermography', SPIE Proceedings Series, 4020, pp. 174181,2000

[13] C. Wallbrink, S. A. Wade, and R. Jones, "The effect of size on the quantitative estimation of defect depth in steel structures using lock-in thermography" J. Appl. Phys. 101, 104907, 2007

[14] M. Choi, K. Kang, J. Park, W. Kim, K. Kim, Quantitative determination of a subsurface defect of reference specimen by lock-in infrared thermography, NDT\&E Int., 41, p. 119-124, 2008

[15] D. Peng , R. Jones, Lock-in thermographic inspection of squats on rail steel head Infrared Physics \& Technology 57 89-95, 2013

[16] A Mendioroz, A Castelo, R Celorrio, A Salazar, Characterization of vertical buried defects using lock-in vibrothermography:I. Direct problem, Meas. Sci. Technol. 24065601 (11pp), 2013

[17] N. W. Pech-May, A. Oleaga, A. Mendioroz, A. J. Omella, R. Celorrio, A. Salazar, Vertical cracks characterization using lock-in thermography: I infinite cracks, Meas. Sci. Technol. 25, 115601 (10pp), 2014

[18] M. Streza, Y. Fedala, J.-P. Roger, G. Tessier, C. Boué, Heat transfer modeling for surface crack depth evaluation, Meas. Sci. Technol. 24, 045602 (6pp), 2013

[19] Y. Fedala, M. Streza, J.-P. Roger, G. Tessier, C. Boué, Open cracks depth sizing by laser stimulated Infrared lock-in thermography, J. Phys. D: Appl. Phys. 47, 465501 (6pp), 2014

[20] C. Boué, G. Tessier, J.-P. Roger, M. Streza, Procédé d'évaluation de la profondeur d'une fissure French Patent Application n ${ }^{\circ} 12$ 58940, PCT/FR2013/052185, CNRS - UPMC, 2013

[21] C. Boué, G. Tessier, J.-P. Roger, M. Streza, Method for assessing the depth of a crack, US Patent, publication number 2015-0241212, 2015

[22] H.S. Carslaw, J.C. Jaeger, Conduction of Heat in Solids, $2^{\text {nd }}$ ed, Oxford Press, 1959. p. 16

[23] Y. Fedala, M. Streza, F. Sepulveda, J.-P. Roger, G. Tessier, C. Boué, Infrared lock-in thermography crack localization on metallic surfaces for industrial diagnosis, Journal of Non Destructive Evaluation, DOI 10.1007/s10921-013-0218-4, 2013 
[24] C. Boué , S. Holé, Infrared thermography protocol for simple measurements of thermal diffusivity and conductivity, Infrared Phys. Tech. 55 376-79, 2012 
Steve Beuve and Zihi Qin were students of sensors, instrumentation \& mesurements master at Pierre \& Marie Curie University, Paris, France.

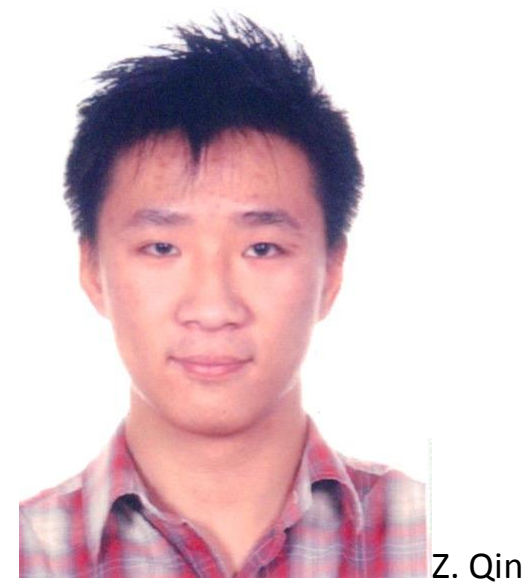

No photo for S. Beuve 
Christine Boué received her Ph.D. degree in electrical engineering in 1991 from the University Pierre et Marie Curie in association with the Ecole Supérieure de Physique et de Chimie Industrielles, Paris France. During her Ph.D. thesis, she studied the distribution of space charges in piezoelectric polymers. She is currently an Associate Professor at Sorbonne Universités-UPMC (France) since 1992 where she teaches electronics, microcontroller interfacing, signal processing. Her research topics concern thermal imaging and non-destructive testing by synchronous infrared thermography.

e-mail: christine.boue@espci.fr

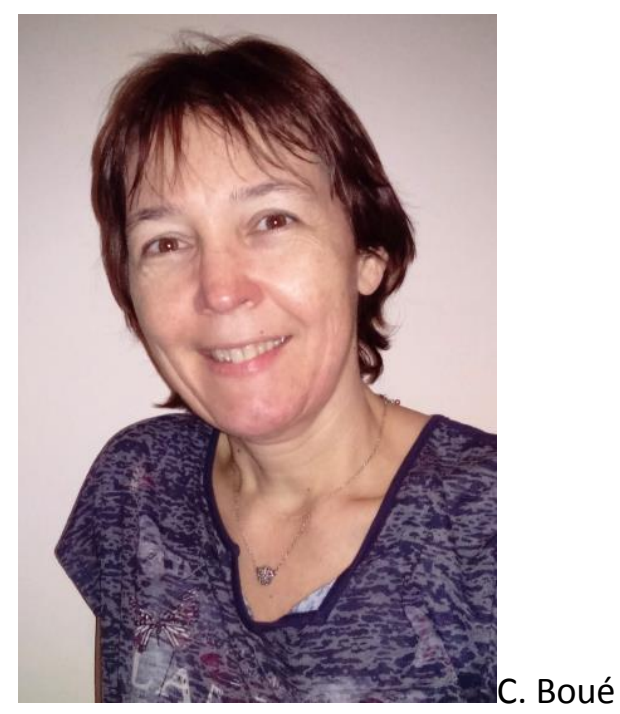


Stéphane Holé joined Laboratoire d'Électricité Générale of École Supérieure de Physique et de Chimie Industrielles (Paris, France) to study an instrument for measuring fast development of space charges in insulators under rapid voltage variations. It was the topic of his PhD he received in 1996. Currently Professor at Université Pierre et Marie Curie, he leads the Instrumentation Group in Laboratoire de Physique et d'Étude des Materiaux since 2007. His research topics are various such as space charge in insulators and semiconductors (main topic), electrostatic, magnetostatic and ultrasonc sensors. He received the Jack Hollingum Award in 2002 and 2004, and obtained his Habilitation in 2007. He teaches solid state physics, electronics and sensor physics. He is coordinator of the sensors, instrumentation \& mesurements master at Pierre \& Marie Curie University since 2009.

e-mail: stephane.hole@espci.fr

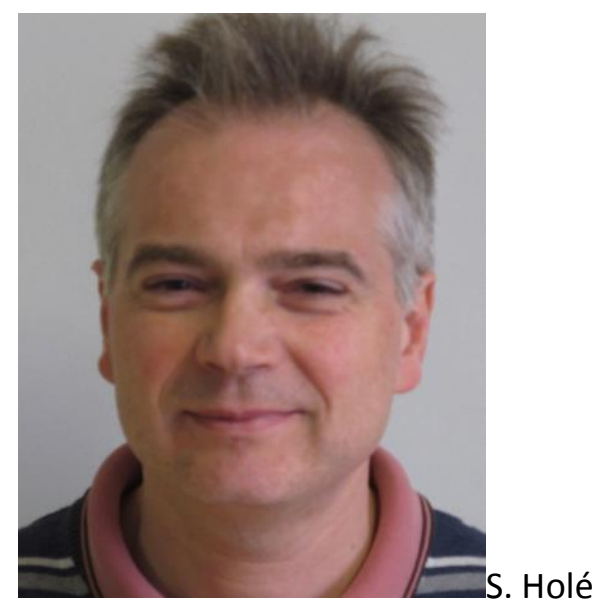


Jean Paul Roger is associate professor at the Langevin Institute, ESPCI ParisTech (France). He received the PhD degree in physical sciences from Pierre and Marie Curie University in 1988. His main research fields are: thermal characterization of materials, thin films and structures using optically based photothermal techniques (mirage detection, photoreflectance microscopy, dynamic ellipsometry), and development of interferometric, reflectance and ellipsometric microscopy imaging techniques to measure the displacement fields of actuated micromechanical systems and/or to map films growth.

e-mail: jean-paul.roger@espci.fr

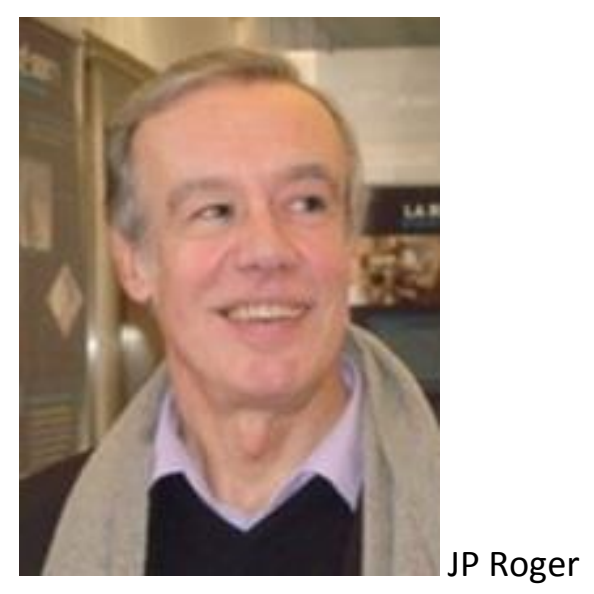




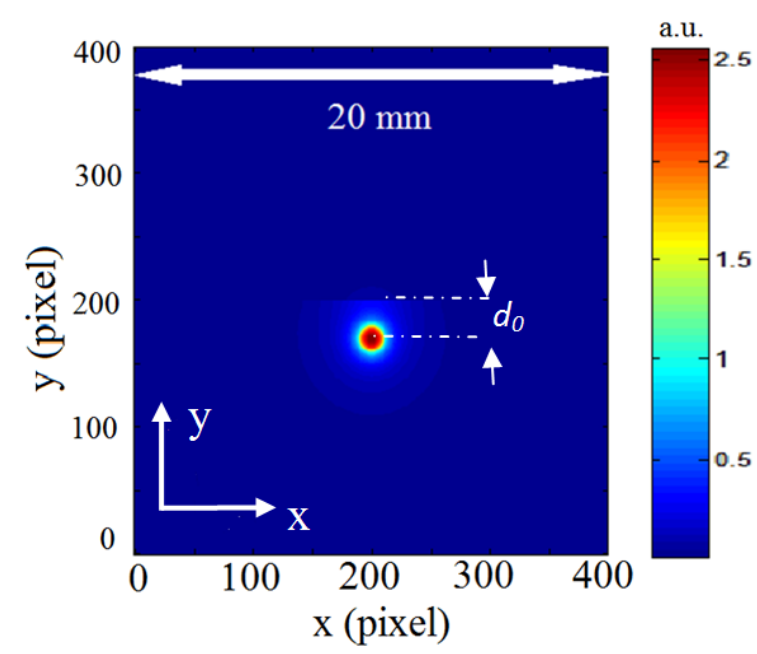

(a)

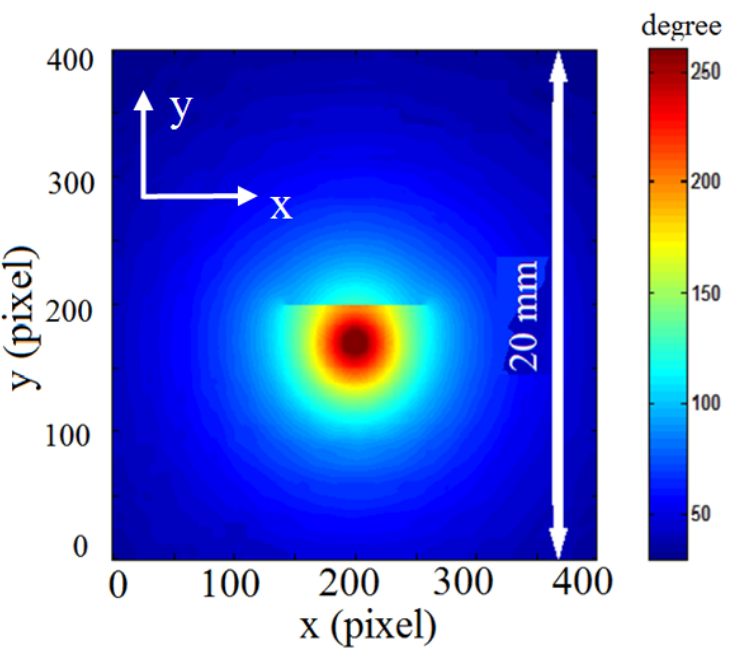

(b)

Figure 1: (a) amplitude image, (b) phase image.

Simulation parameters are $w=30 \mu \mathrm{m}, h=1 \mathrm{~mm}, L=6 \mathrm{~mm}, r=0.5 \mathrm{~mm}, d_{0}=1.5 \mathrm{~mm}, \alpha=3.310^{-6} \mathrm{~m}^{2} / \mathrm{s}$, $f=0.8$ Hz. a.u.: arbitrary unit. 


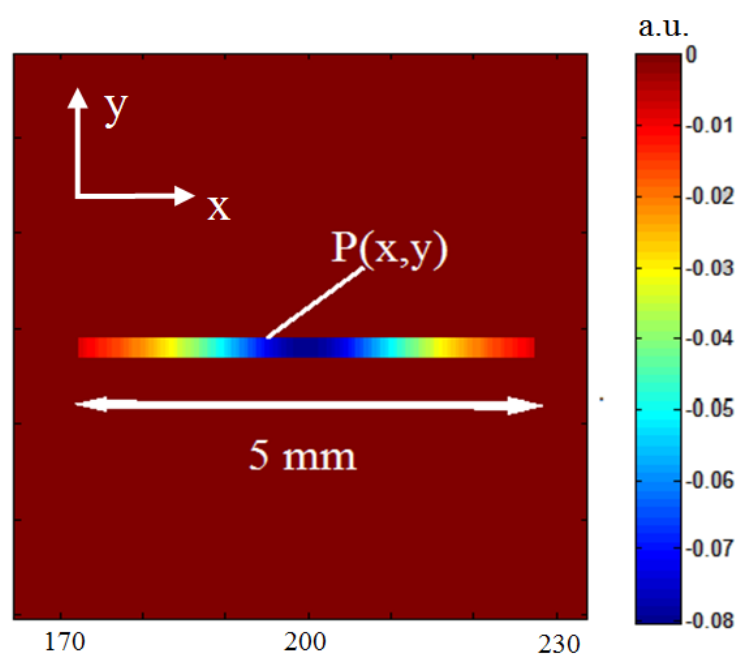

(a)

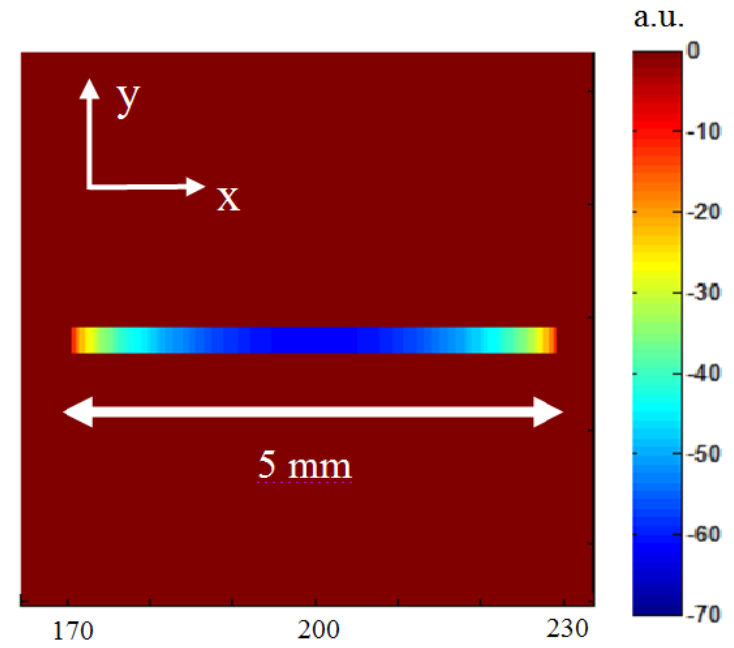

(b)

Figure 2: Pixels $\mathrm{P}(\mathrm{x}, \mathrm{y})$ extracted from the Laplacian of Figure 1 images $(f=0.8 \mathrm{~Hz})$,

(a) Laplacian of the amplitude. (b) Laplacian of the phase. a.u.: arbitrary unit. 


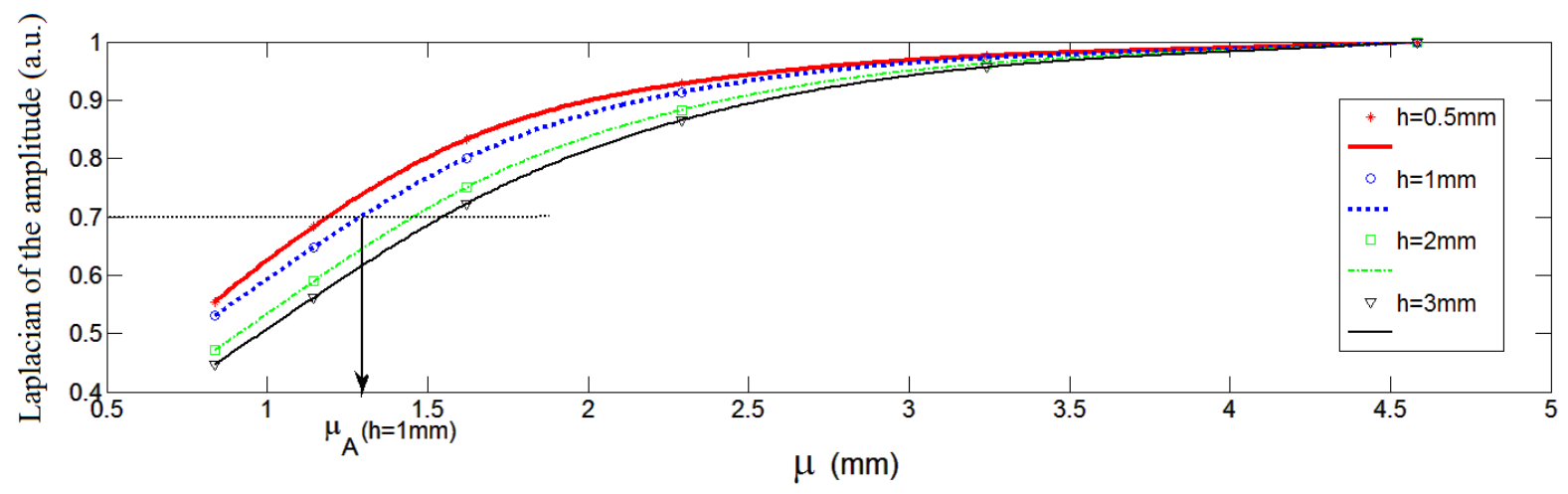

Figure 3: Simulated $\Lambda_{N}\left(\mu_{i}\right)$ and polynomial fit $f_{h}(\mu)$ at the pixel P $\left(d(x, y)=d_{0}\right)$ for different depth $h$. Simulation parameters are $r=0.5 \mathrm{~mm}, \alpha=3.310^{-6} \mathrm{~m}^{2} / \mathrm{s}, d_{0}=1.5 \mathrm{~mm}, w=30 \mu \mathrm{m}, L=6 \mathrm{~mm}$. 


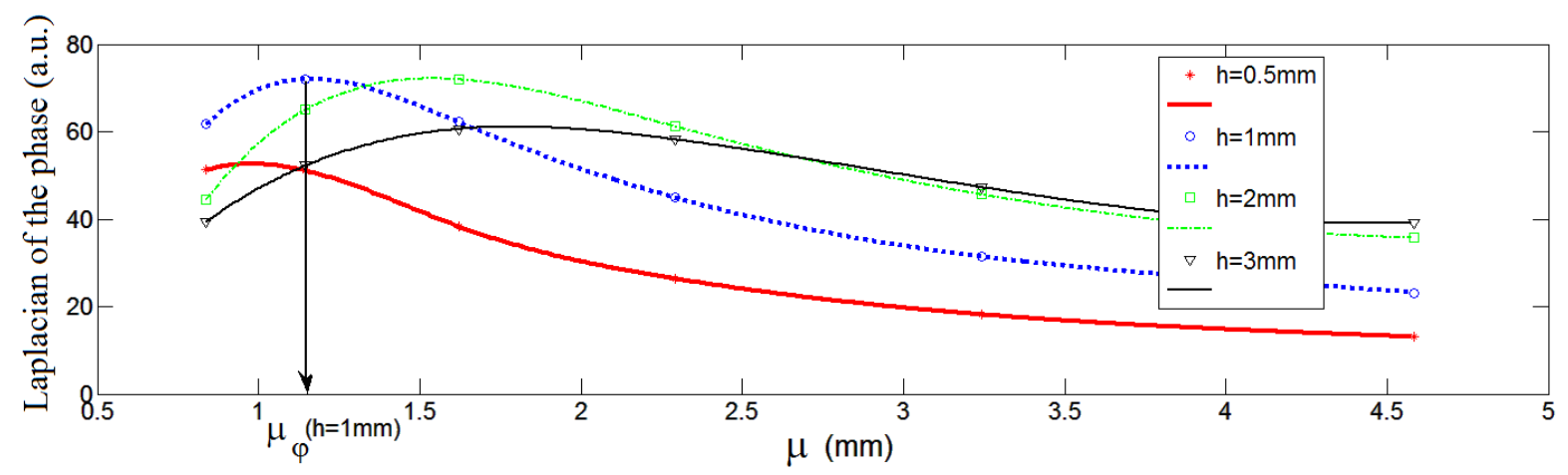

Figure 4: simulated $\Lambda_{\varphi}\left(\mu_{i}\right)$ and polynomial fits at the pixel P $\left(d(x, y)=d_{0}\right)$ for different depths $h$.

Simulation parameters are $r=1 \mathrm{~mm}, \alpha=3.310^{-6} \mathrm{~m}^{2} / \mathrm{s}, d_{0}=1.5 \mathrm{~mm}, w=30 \mu \mathrm{m}, L=6 \mathrm{~mm}$. 


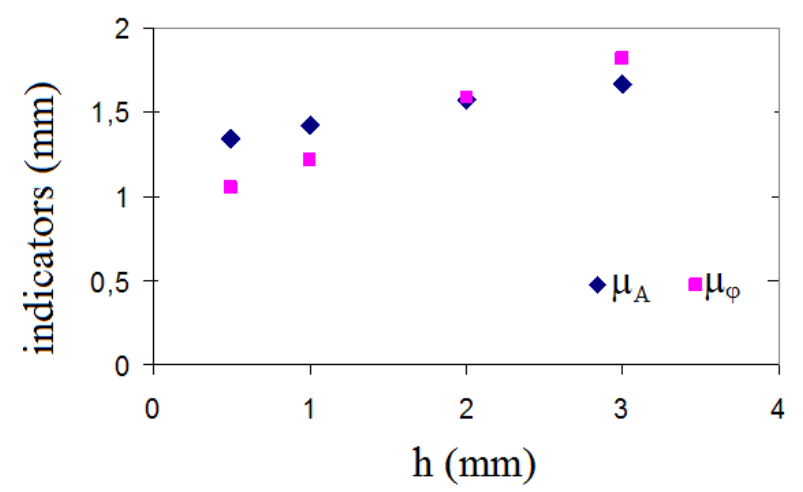

Figure 5: $\mu_{A}$ and $\mu_{\varphi}$ as a function of simulated depth $h$ at the pixel P $\left(d(x, y)=d_{0}\right)$. 

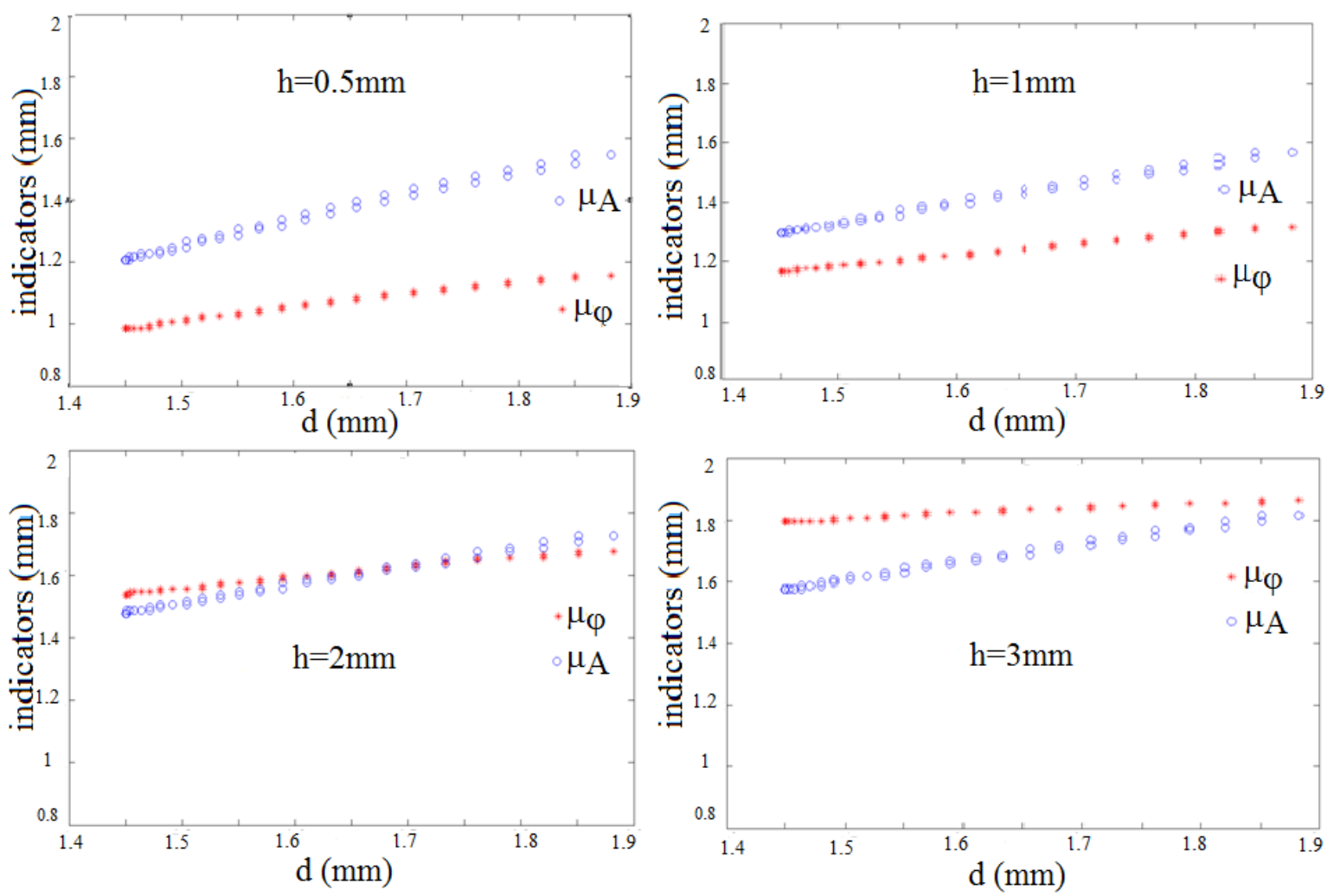

Figure $6: \mu_{A}$ and $\mu_{\varphi}$ as a function of the distance $d$ for the 4 simulated depths $h$ 


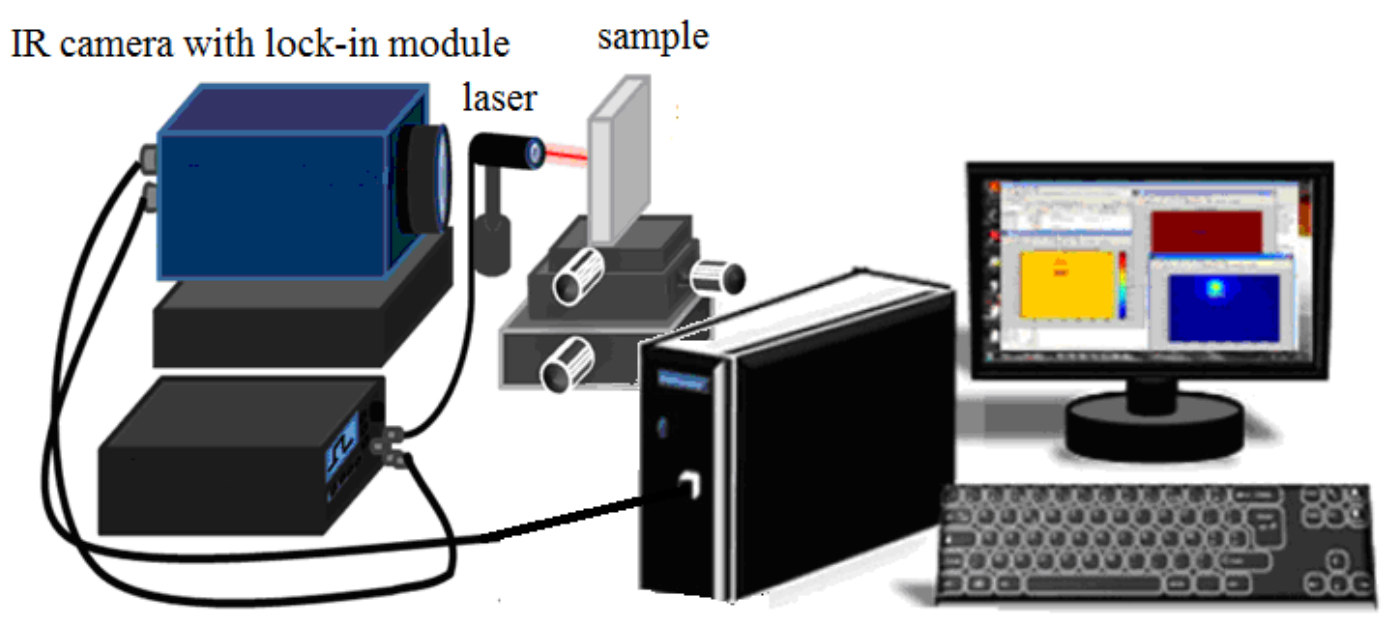

signal generator

Figure 7: experimental set-up. 

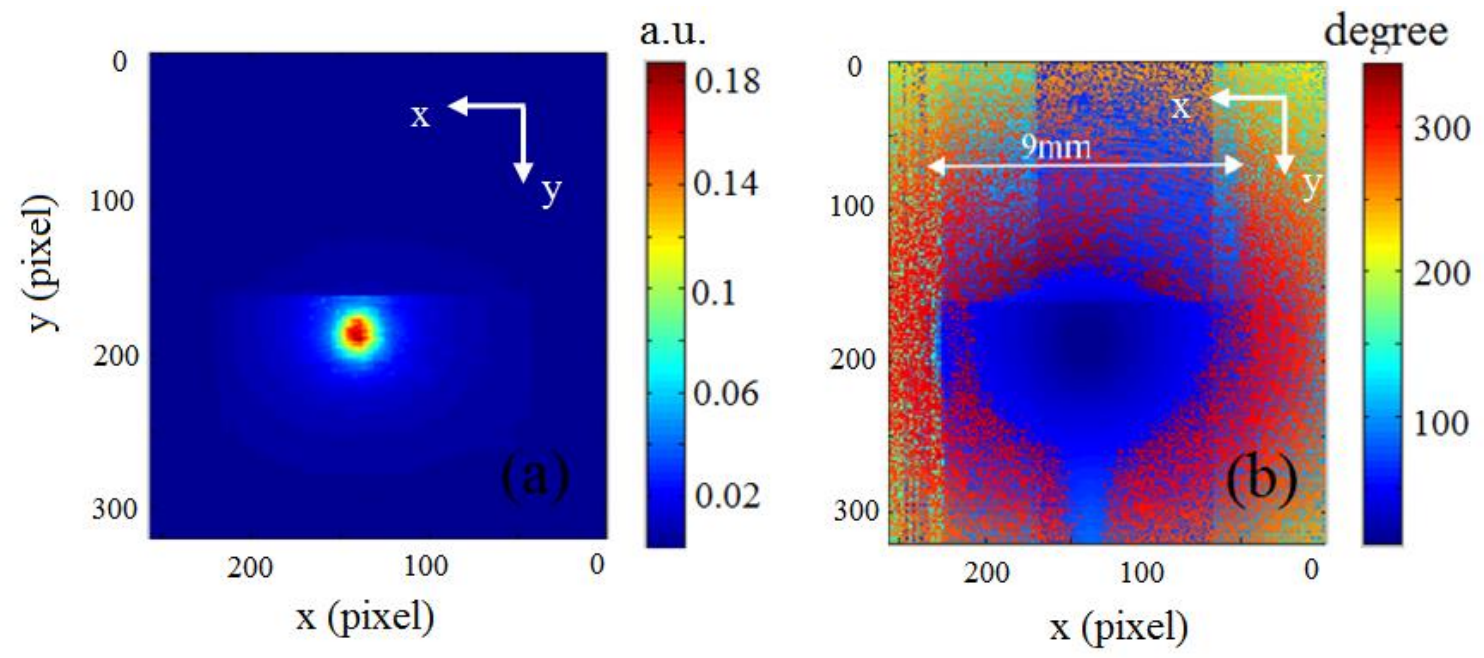

a.u.
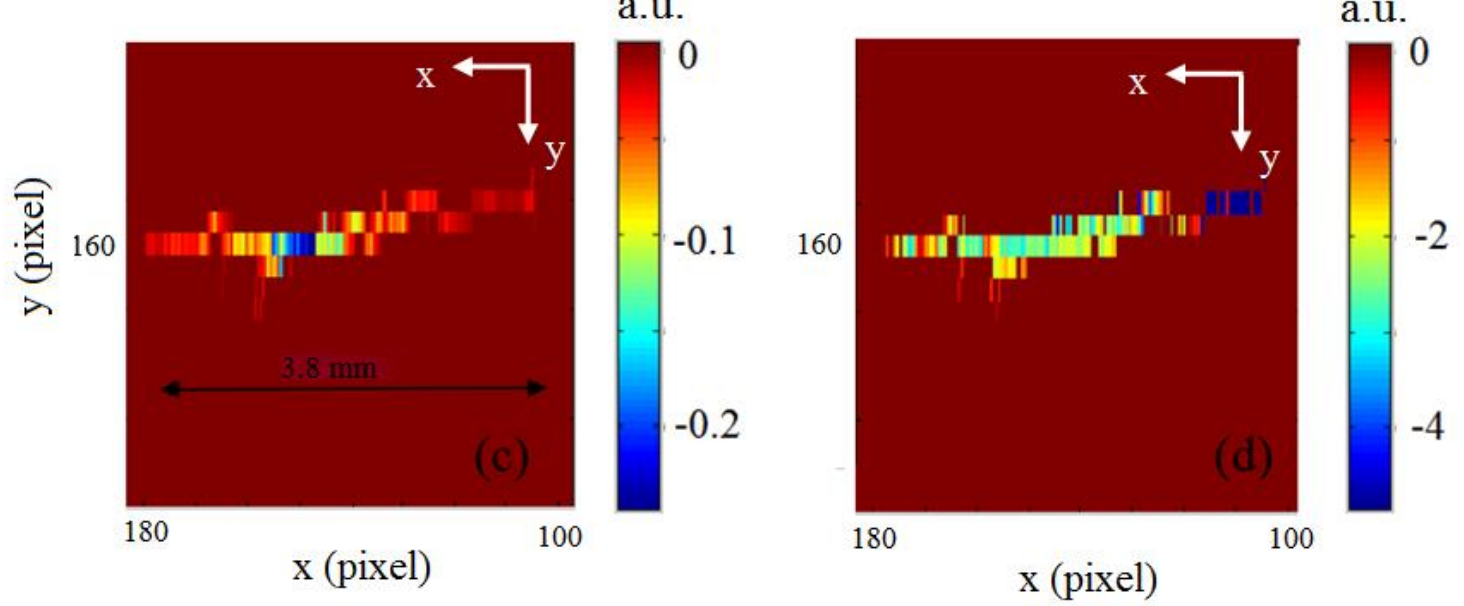

Figure 8: example of a fatigue crack. (a) Amplitude image, (b) Phase image, (c) Laplacian of the amplitude of the selected $\mathrm{P}(\mathrm{x}, \mathrm{y})$ pixels calculated using Figure $8 \mathrm{a}$, (d) Laplacian of the phase for the selected pixels calculated using Figure 8b. $f=0.05 \mathrm{~Hz}, 1$ pixel corresponds to $50 \mu \mathrm{m} * 50 \mu \mathrm{m}$. a.u.: arbitrary unit. 

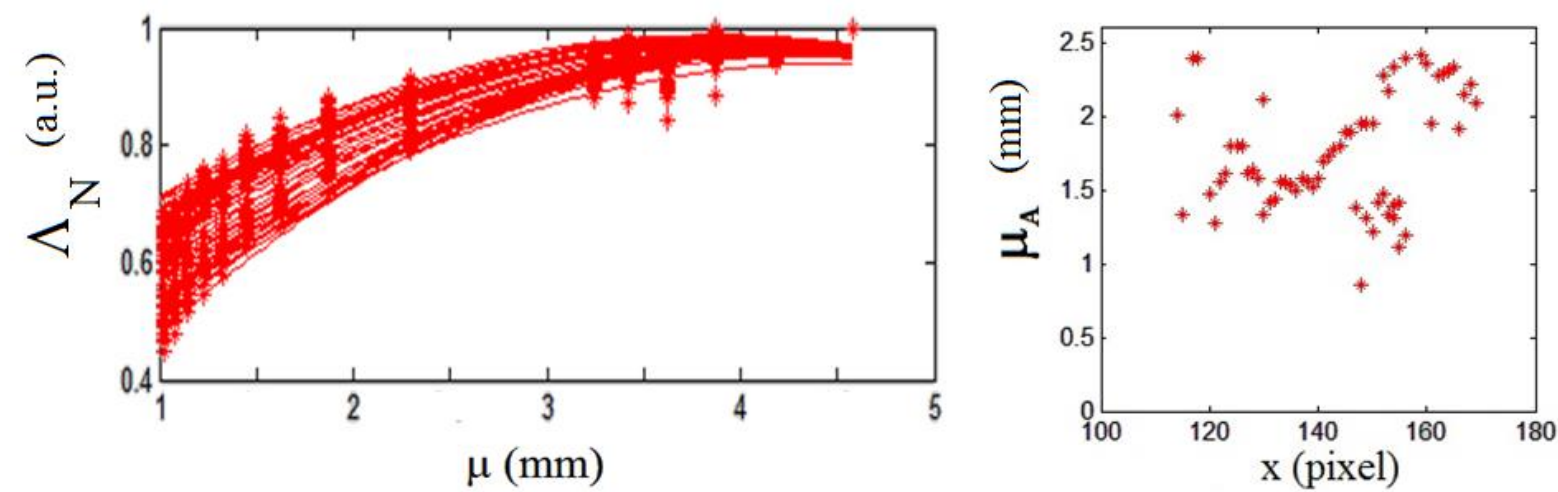

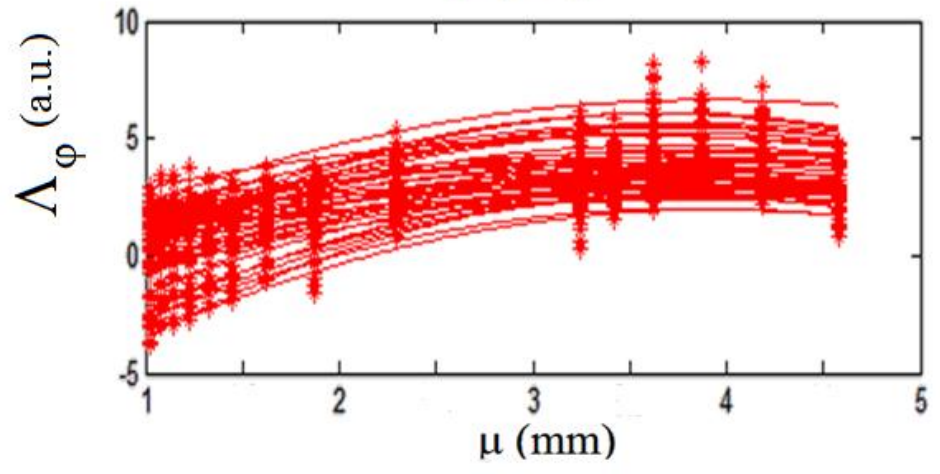

(a)

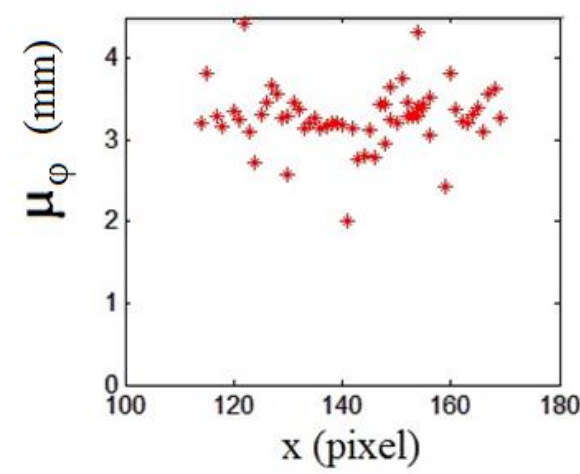

(b)

Figure 9: (a) Experimental $\Lambda_{N}$ and $\Lambda_{\varphi}$ and polynomial fits as a function of $\mu$ for the selected pixels in the sample of figure 8. (b) Deduced $\mu_{\mathrm{A}}$ and $\mu_{\varphi}$ for the selected pixels along the $\mathrm{x}$ direction. $f$ is varying from $0.05 \mathrm{~Hz}$ to $1.5 \mathrm{~Hz}$. 


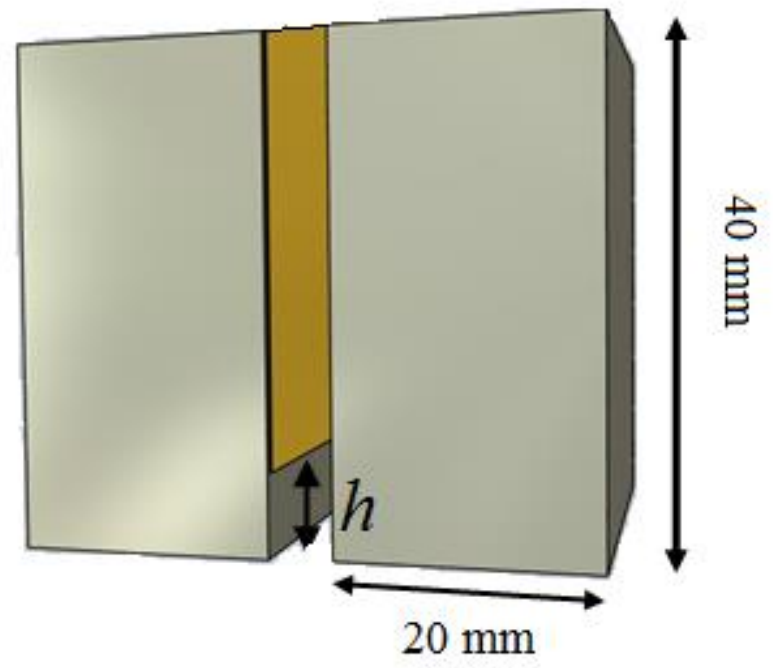

Figure 10: simulation of a controlled depth crack in a steel or aluminum alloy sample. The brass sheet exhibits a constant $h$ cut. 

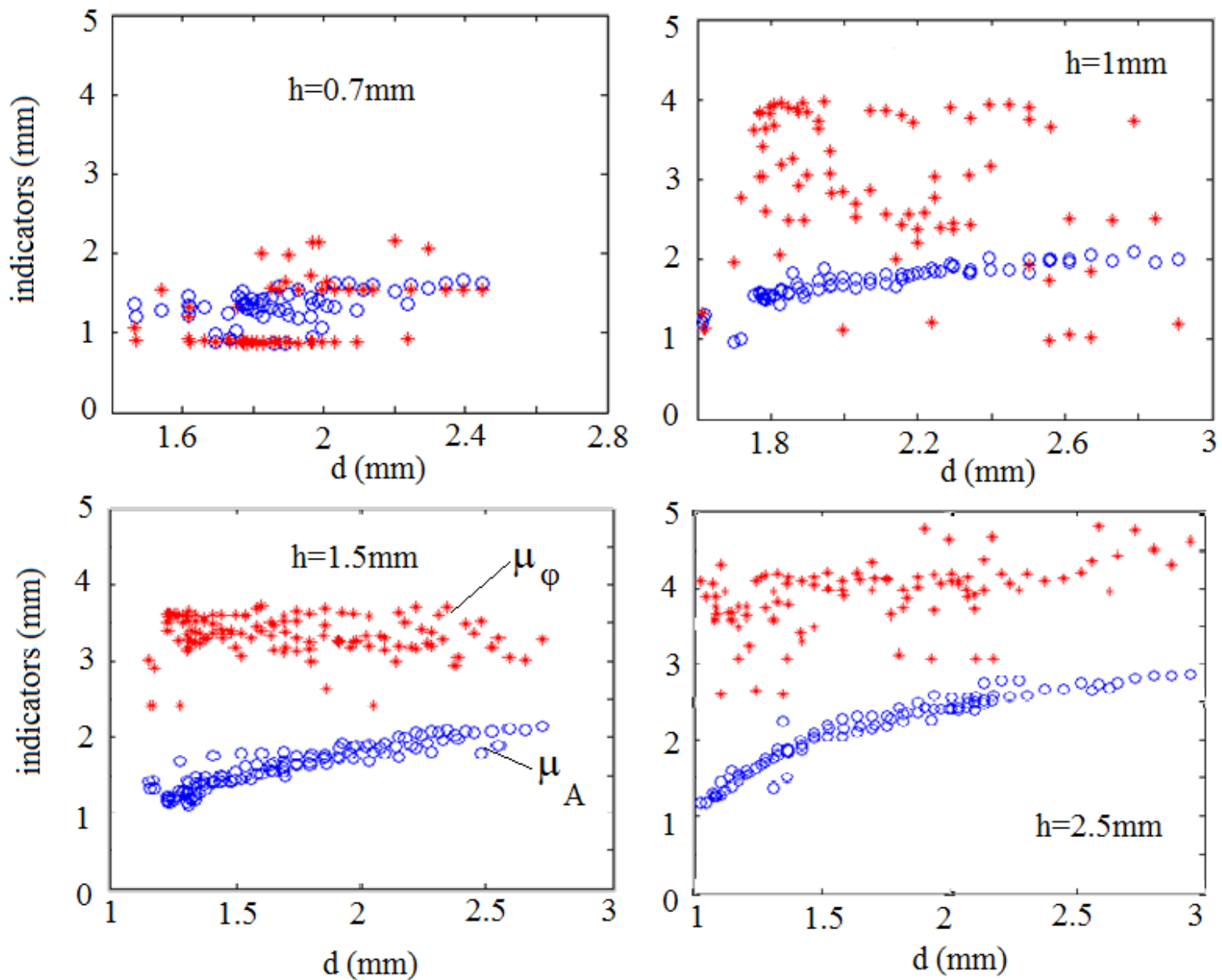

Figure 11: $\mu_{A}$ (blue circle) and $\mu_{\varphi}$ (red star) responses as a function of distance $d$ for four depth $h$. 


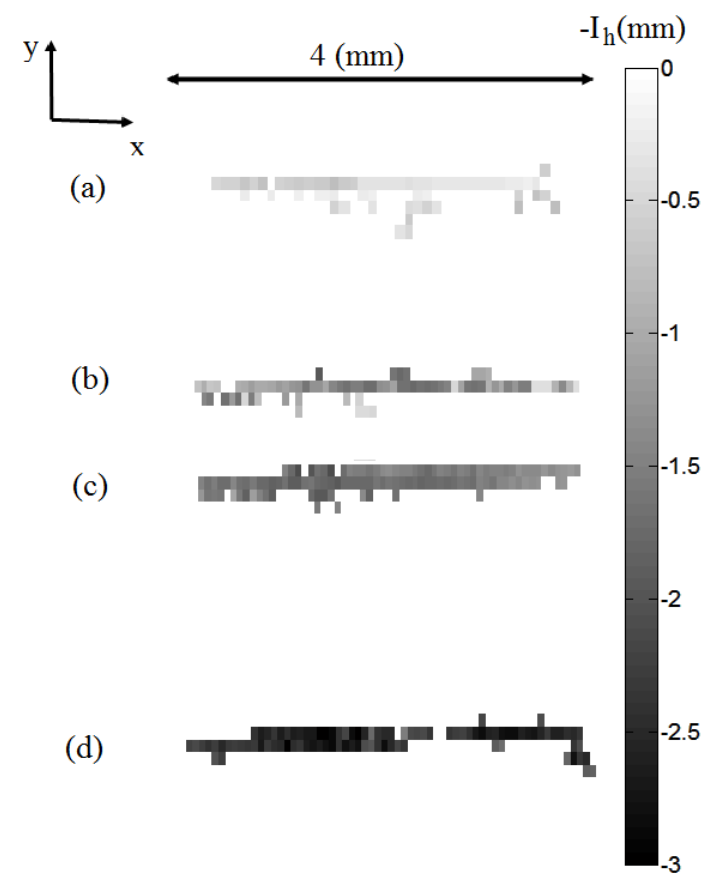

Figure 12: $I_{h}$ for the selected pixels in x,y plane. 1 pixel represents $80 \mu \mathrm{m} * 80 \mu \mathrm{m}, a=2$.

The color indicates (negative) $I_{h}$ evaluation of each selected pixels. (a) Steel sample F1, expected depth around $0.7 \mathrm{~mm}$, (b) Aluminum alloy sample G, expected depth around $1 \mathrm{~mm}$, (c) Steel sample F2, expected depth around $1.5 \mathrm{~mm}$, (d) steel sample F3, expected depth around $2.5 \mathrm{~mm}$. 

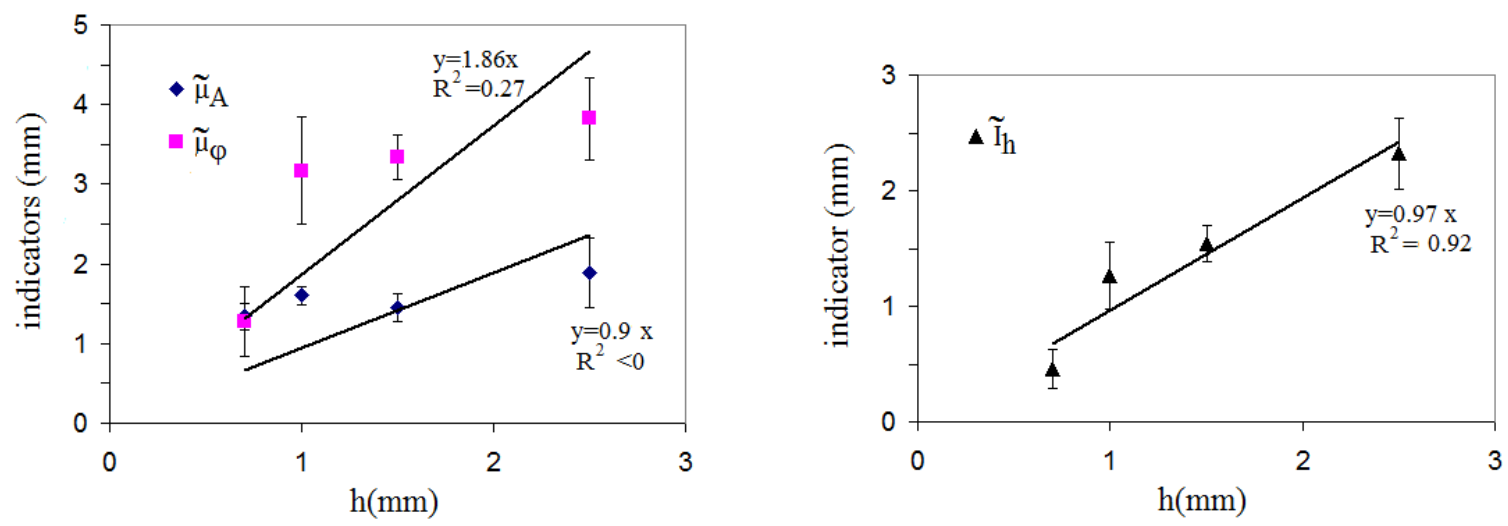

Figure 13: $\tilde{\mu}_{A}, \tilde{\mu}_{\varphi}$ indicators (left) and $\tilde{I}_{h}$ indicator (right) as a function of expected $h$ values obtained on the steel and aluminum alloy samples. Estimate slope of linear regression through the origin and R-squared coefficient $\mathrm{R}^{2}$ are added for each indicators. 
(a)

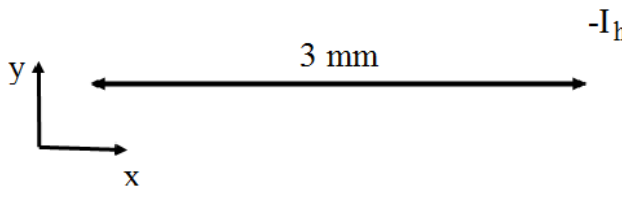

$-\mathrm{I}_{\mathrm{h}}(\mathrm{mm})$

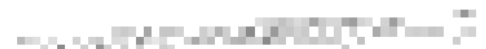

(b)

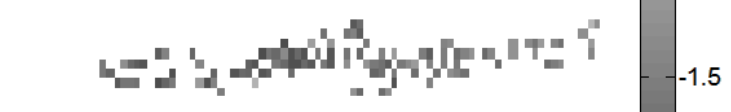

(c)

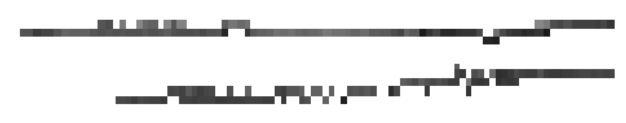

(d)

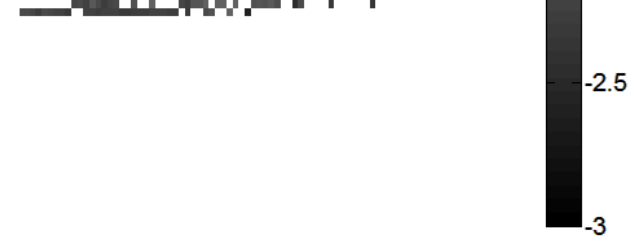

Figure 14: $I_{h}$ for the selected pixels as a function of pixel location in $(\mathrm{x}, \mathrm{y})$ plane,

1 pixel represents $50 \mu \mathrm{m} * 50 \mu \mathrm{m}$. (a) Inconel sample A, expected depth around $0.4 \mathrm{~mm}$, (b) Inconel sample B, expected depth around $1.6 \mathrm{~mm}$, (c) Inconel sample D, expected depth around $2.1 \mathrm{~mm}$, (d) Inconel sample E, expected depth around $3.2 \mathrm{~mm}$. 

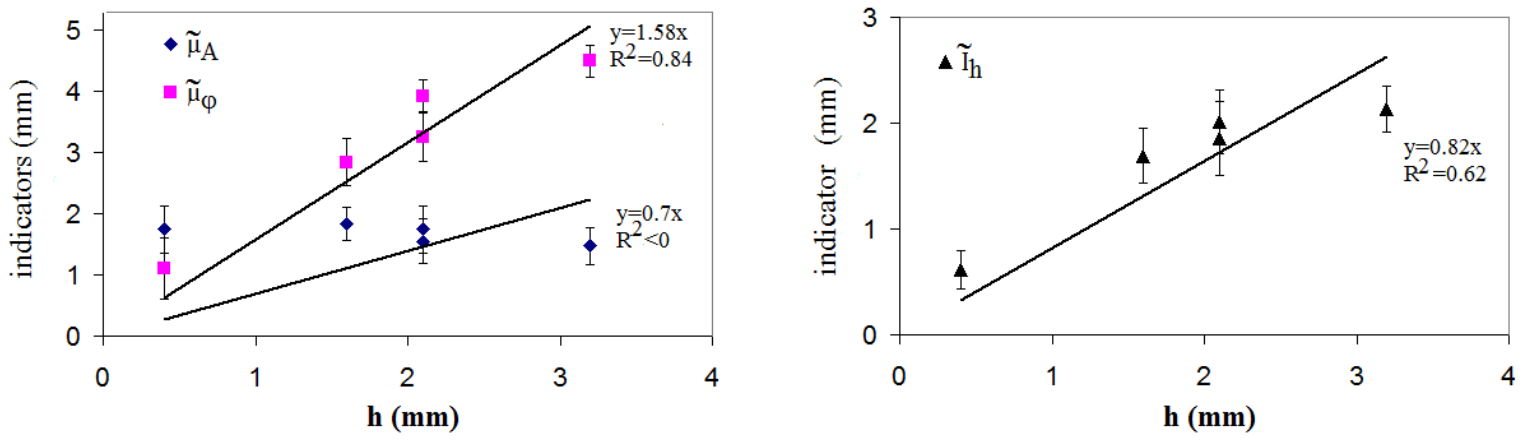

Figure 15: $\tilde{\mu}_{A}, \tilde{\mu}_{\varphi}$ indicators (left) and $\tilde{I}_{h}$ indicator (right) as a function of expected $h$ values obtained on the Inconel alloy samples. Estimate slope of linear regression through the origin and $\mathrm{R}$-squared coefficient $\mathrm{R}^{2}$ are added for each indicators. 
Table 1: crack sizes of steel and aluminum alloy samples

\begin{tabular}{|l|l|l|}
\hline & Controlled depth $h(\mathrm{~mm})$ & crack width $(\mu \mathrm{m})$ measured by optical microscopy \\
\hline F1 - steel & $0.7 \pm 0.1$ & $30 \pm 5$ \\
\hline G - aluminum alloy & $1 \pm 0.1$ & $30 \pm 5$ \\
\hline F2 - steel & $1.5 \pm 0.1$ & $30 \pm 5$ \\
\hline F3 - steel & & \\
\hline
\end{tabular}


Table 2: crack sizes of Inconel alloy samples

\begin{tabular}{|l|l|l|l|l|}
\hline Inconel & \multicolumn{2}{|l|}{$\begin{array}{l}\text { Depth }(\mathrm{mm}) \text { on the two lateral } \\
\text { sides of the sample }\end{array}$} & $\begin{array}{l}\text { averaged depth (mm) deduced from } \\
\text { the values of the first columns }\end{array}$ & $\begin{array}{l}\text { crack width } \\
(\mu \mathrm{m})\end{array}$ \\
\hline Sample A & $0.2 \pm 0.1$ & $0.6 \pm 0.1$ & 0.4 & $20 \pm 10$ \\
\hline Sample B & $1 \pm 0.1$ & $2.1 \pm 0.1$ & 1.6 & $40 \pm 10$ \\
\hline Sample C & $1.1 \pm 0.1$ & $3.1 \pm 0.1$ & 2.1 & $35 \pm 5$ \\
\hline Sample D & $1.7 \pm 0.1$ & $2.4 \pm 0.1$ & 2.1 & $65 \pm 5$ \\
\hline Sample E & $2.8 \pm 0.1$ & $3.6 \pm 0.1$ & 3.2 & $45 \pm 5$ \\
\hline
\end{tabular}

